\title{
Materials to facilitate orbital reconstruction and soft tissue filling in posttraumatic orbital deformaties
}

\author{
Ling-Xiao Ye, Xiao-Ming Sun, Yu-Guang Zhang, Ying Zhang \\ Department of Plastic and Reconstructive Surgery, Ninth People's Hospital affiliated to the Medical School of Shanghai Jiao Tong \\ University, Shanghai 200011, China.
}

Address for correspondence: Dr. Ying Zhang, Department of Plastic and Reconstructive Surgery, Ninth People's Hospital affiliated to the Medical School of Shanghai Jiao Tong University, 639 Zhi Zao Ju Road, Shanghai 200011, China. E-mail: zyinghh@163.com

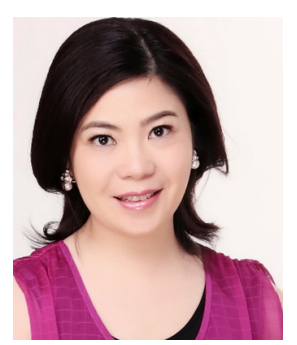

Dr. Ying Zhang, M.D., The vice professor of Department of Plastic and Reconstructive Surgery, Shanghai Ninth People's Hospital, Jiao Tong University. Graduated from Shanghai Jiaotong University School of Medicine, 6/2004. Major in the reconstruction of facial deformities and facial rejuvenation. The member of China Physician's Society of Plastic Ophthalmology, Operation Smile and International Aesthetic Plastic Association.

\begin{abstract}
Posttraumatic orbital reconstruction has been a challenging mission for decades in craniomaxillofacial surgery. Complications like enophthalmos, diplopia and gaze obstacles emerge when orbital trauma occurs, affecting people's daily life as well as their appearance. Advances in technology and research gained through years of experience has provided us with a greater understanding of the changes following trauma, as well as providing us with a variety of filling materials that we can choose from to handle the deformities. However, the best type of material for repair of orbital deformities remains controversial. This paper reviewed approximately 60 articles discussing materials used in orbital reconstruction or soft tissue defect filling in the past years, with the aim of giving a comprehensive overview of the advantages and disadvantages of materials used in this field so as to help surgeons to make a better choice.
\end{abstract}

Key words:

Orbital reconstruction; soft tissue filling; materials; enophthalmos

\section{INTRODUCTION}

Orbital fracture is common in facial trauma. Its incidence ranges from $18 \%$ to $50 \%$ of all craniomaxillofacial traumas, considering the difference of the geographic region, injury mechanism and study population. ${ }^{[1]}$ Although the

\begin{tabular}{|c|c|}
\hline \multicolumn{2}{|c|}{ Access this article online } \\
\hline Quick Response Code: & \\
\hline & http://parjournal.net \\
\hline & $\begin{array}{l}\text { DOI: } \\
10.20517 / 2347-9264.2015 .122\end{array}$ \\
\hline
\end{tabular}

eye is well protected by the strong orbital rim, the thin orbital floor, and the medial wall that acts as a shock absorber, there is a high chance of associated ocular injuries after orbital trauma, ranging from $22 \%$ to $76 \%{ }^{[2]}$

This is an open access article distributed under the terms of the Creative Commons Attribution-NonCommercial-ShareAlike 3.0 License, which allows others to remix, tweak and build upon the work non-commercially, as long as the author is credited and the new creations are licensed under the identical terms.

For reprints contact: service@oaepublish.com

How to cite this article: Ye LX, Sun XM, Zhang YG, Zhang Y. Materials to facilitate orbital reconstruction and soft tissue filling in posttraumatic orbital deformaties. Plast Aesthet Res 2016;3:86-91.

Received: 21-11-2015; Accepted: 10-12-2015 
If the traumas are not diagnosed or well treated in a timely fashion, patients can suffer from functional and aesthetic sequelae.

In 1889, Lang $^{[3]}$ was first to recognize that traumatic enophthalmos is caused by fracture of the orbital wall and the associated orbital tissue abnormality. Significant progress has been made in the field of orbital reconstruction. It's commonly believed that orbital deformities occur because of two main causes: first, the anatomic changes behind the eyeball that may consist of an inferior dislocation of the orbital floor or a transversal expansion of the orbit which contributes to the defect; ${ }^{[4]}$ second, once soft tissue within the socket is affected, the whole socket can be influenced. Thus, we are supposed not only to repair the orbital fracture, but also find the appropriate filling materials to restore the volume of orbit, avoiding bothersome sequelae, and restore ocular functions.

Orbital fractures occur with bothersome complications like enophthalmos and constant diplopia. Among 55 studies performed on orbital reconstruction, it was found that the indication for surgery was based on diplopia in $18.3 \%$ of cases and on preoperative enophthalmos in $29.8 \%$ of cases. ${ }^{[5]}$ The goal of orbital reconstruction is to repair trauma defects, to correct the anatomical position of the eye, to accurately restore the volume of the orbit, to avoid sequelae such as enophthalmos, and to restore ocular function. Orbital fractures can occur alone or with other craniomaxillofacial fractures, which may complicate the reconstruction. It's reported that the medial wall and the orbital floor fractures are the most frequent type. The medial wall of the orbit consists of the maxilla, lacrimal, ethmoid and sphenoid bones, and it is the most vulnerable and most complicated to repair due to its anatomical structure. Small defects may heal alone by the formation of scar tissue, whereas larger defects, especially those associated with enophthalmos and hypoglobus, need material of a sufficient strength to support the orbital contents and restore the contour of the orbit. ${ }^{[6]}$

In terms of operation, we should consider three pivotal questions. When is the best timing to perform the operation? How to perform the operation? What materials should be used? This review aims to give a comprehensive overview of the advantages and disadvantages of materials used to repair orbital fractures or used for soft tissue defect filling, with the goal of assisting surgeons to make a better choice.

\section{THE IDEAL IMPLANT MATERIAL FOR ORBITAL FRACTURE RECONSTRUCTION}

It's very difficult to determine which material is the ideal implant for orbital fracture reconstruction. The ideal characteristics of the material used as an orbital implant include: (1) ability to bend into an anatomical shape; (2) radiopacity; and (3) permanent stability. ${ }^{[5]}$ For smaller defects, the strength of the implant holds limited relevance for a successful outcome, and the choice of implant is more dependent on biocompatibility. ${ }^{[7]}$ In larger fractures, mechanical properties, biocompatibility, and the contour or form factor needs special attention. ${ }^{[8]} \mathrm{A}$ recent article argues that the ideal implant should be discussed in seven points: (1) stability and fixation; (2) contouring and handling; (3) biological behavior; (4) drainage; (5) donor site morbidity; (6) radiopacity; and (7) availablility and cost-effectiveness. ${ }^{[5]}$

First of all, the ideal material is expected to be strong enough to support the orbital content, to be stable, to maintain its shape over time, and to fix itself to surrounding structures. Second, it should be malleabile with a smooth surface. A desirable implant needs to be of high biocompatibility, chemically inert, non-allergenic and non-carcinogenic to ensure a decrease in rates of infection/extrusion/migration/ foreign body reaction. It must allow high tissue incorporation with minimal resorption. Furthermore, spaces within the implant should be present to allow drainage of orbital fluid. Materials that are radiopaque facilitate postoperative evaluation. Lastly, it should be readily available, in sufficient quantities, and have an acceptable cost to ensure easy popularization.

\section{BIOMATERIALS}

Biological materials including autografts, allografts, and xenografts, are defined as grafts harvested from the same body, from cadavers or from animals. Generally speaking, autologous grafts are characterized by cost-effectiveness but limited availability, variable resorption rates resulting in unpredictable orbital volume that may lead to enophthalmos, associated donor site morbidity (pain, scarring, infection, haematoma), as well as an increased surgical time. Autologous bone was the first material used to reconstruct the orbit and remains popular today. Since the 18 th century, it has been the "gold standard" biomaterial for the reconstruction of craniofacial bony defects. ${ }^{[9,10]}$ The major donor sites include crista iliaca, calvarium, maxilla and mandible. ${ }^{[11-14]}$ Autologous bone graft is applied in orbital reconstruction because of its strength, rigidity, biocompatibility, vascularization potential, and incorporation into the orbital tissue with minimal acute and chronic immune reactivity. The advantages mentioned above make it a significant role in the stage of orbital

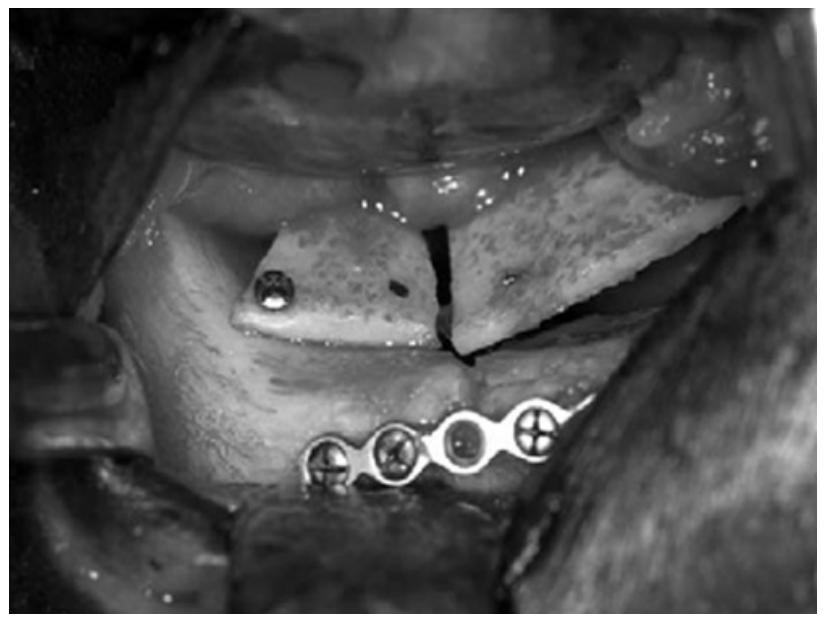

Figure 1: Multiple small plates of calvarial bone and screws were used to re-create the normal contour of the orbit. Adapted from Gunarajah and Samman ${ }^{[6]}$ 
reconstruction. However, its poor malleability, donor site morbidity and fluctuant resorption rates may be problematic [Figure 1]. The unpredictable resorption rates of autologous bone especially iliaca can even reach $80 \%$, which increase the risk of complications. ${ }^{[13]}$ Resorption may be decreased by fixating of the graft, which promotes revascularization and osteoconduction. ${ }^{[15]}$

Another option is cartilage graft, which compared to the "gold standard" bone graft is easier to harvest, is more malleable, and has less resorption. ${ }^{[16]}$ The nasal septum, conchal cartilage and costal cartilage are the common donor sites. The nasal septum is advantageous owing to the rapid harvest time and the minimal cosmetic and functional morbidity..$^{[17,18]}$ Bayat et al. ${ }^{[19]}$ performed a randomized clinical trial and found a superior effect for nasal cartilage compared to conchal cartilage with respect to the incidence of enophthalmos at the 3-6 months follow-up point. Whereas, the autologous cartilage still cannot avoid donor site morbidity and is limited in quantity.

Allograft is transplanted tissue from human cadaver. Lyophilized dura mater, demineralized human bone, lyophilized cartilage, irradiated fascia lata are types of harvested tissues. The advantages of allograft include a decreased surgical time, preoperative customizability, absence of donor site morbidity (only in cadavers), and abundant availability. Lyophilized dura (Lyodura) was once the standard for the repair of smaller orbital defects. ${ }^{[20]}$ However, it became controversial after a report of Creutzfeldt-Jakob prion disease in a patient who received dura. ${ }^{[21]}$ The disadvantages of allograft include a resorption rate substantially higher than that of autologous tissue, the necessity for immunosuppressive pharmacotherapy, and potential risk of viral transmission. ${ }^{[22-24]}$

Xenograft mainly includes collagen membrane, porcine sclera, porcine skin gelatin/gelfilm, bovine bone or sclera. It is only rarely used for the repair of orbital fractures because of the association with disease transmission, immunological transplant rejection, and unpredictable and high resorption rates in spite of a reduction in operative time and lack of donor site morbidity. ${ }^{[25]}$

\section{METALS}

Studies have shown that titanium and cobalt alloys used to be active in the stage of orbital skeleton repair. ${ }^{[26]}$ Cobalt alloys seem not that gratifying because of its poor performance in orbital surgery and have gradually been
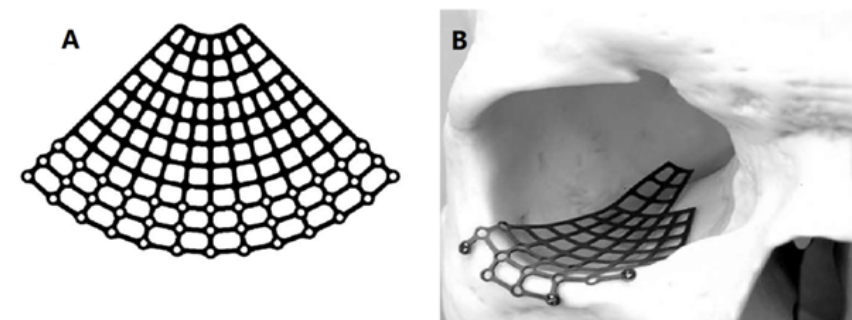

Figure 2: (A) Titanium to be used in orbital reconstruction, especially for large defect; (B) titanium mesh placed in the orbit. Adpated from Ellis and Messo $^{\text {|27 }}$ replaced by titanium.

Titanium mesh has been approved by the Food and Drug Administration since 1984, and now is accepted throughout the would to be used in the craniomaxillofacial surgery, especially in large defects. Titanium is chemically similar to calcium which makes it physiologically inert, and tissue tolerant. Titanium has a high corrosion resistance due to the spontaneously forming thin oxide layers on the surface. This guarantees that the material behaves passively in order not to provoke toxic nor allergic reactions [Figure 2]. ${ }^{[27]}$ Computer-assisted designed and manufactured titanium implants have enabled optimal reconstructive surgery, with the protection of vital structures such as the optic nerve. ${ }^{[28]}$ However, it is costly and may have irregular edges that may impinge on soft tissue. Furthermore, fibrous tissue will incorporate the mesh-holes, which can make implant replacement technically difficult. ${ }^{\text {[2] }}$

\section{POLYMERS}

Polymers are large molecules comprising of multiple repeated subunits, and can be categorized into absorbable and nonabsorbable (permanent), or porous and non-porous types.

Since 1990s, porous ultra-high-density polyethylene (PE, medpor) sheets have been widely used in smaller orbital floor defects [Figure 3]. It's non-absorbable and easily malleable into shapes. The smooth surface of medpor allows tissues within the orbit to move around freely. ${ }^{[26]}$ Connective tissue and vascular components can grow into the pores which provides great biocompatibility. Medpor is reported to be able to achieve similar outcomes and lower infection rates than autologous bone. ${ }^{[8]}$

Non-porous, non-absorbable materials include silicone, ${ }^{[30]}$ polytetrafluoroethylene (teflon), nylon foil. Silicone is cheap, flexible and easy to handle. However, it has unacceptable high rates of extrusion, cyst formation, and infections. Teflon is biologically and chemically inert, non-antigenic with minimal foreign body reaction, sterilizable, and easily moldable. ${ }^{[31]}$ However, with the proven reliability of porous materials, nonporous materials such as polytetrafluoroethylene are not used as frequently. Nylon has been used since 1965 by Browning and Walker with a lot of complications. ${ }^{[32]}$ Recent studies utilize fixation of the implant to the inferior orbital rim in blow-out fractures, demonstrating a complication rate as low as $1.7 \% .^{[33 \mid}$

As for absorbale implants like PLA/PGA, PDS, they have been used in the field of surgery for years with more predictable absorbtion rates as well as higher level of control than biomaterials. They provide temporary support leaving fibrotic tissues. Generally, they are not encouraged to be used in orbital reconstruction considering their unsatisfactory effect and high incidence of complications. ${ }^{[13]}$

\section{BIOLOGICAL CERAMICS}

Hydroxyapatite (HA), which is chemically and crystallographically similar to bone mineral, has been 


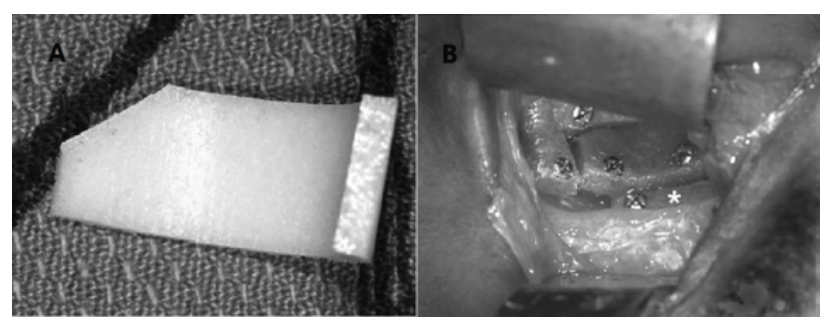

Figure 3: Example of polyethylene for reconstruction of internal orbital defect. (A) Shaped and sized polyethylene; (B) material in the orbit with bone screwed intaoperatively. Adpated from Ellis and Messo ${ }^{[27]}$

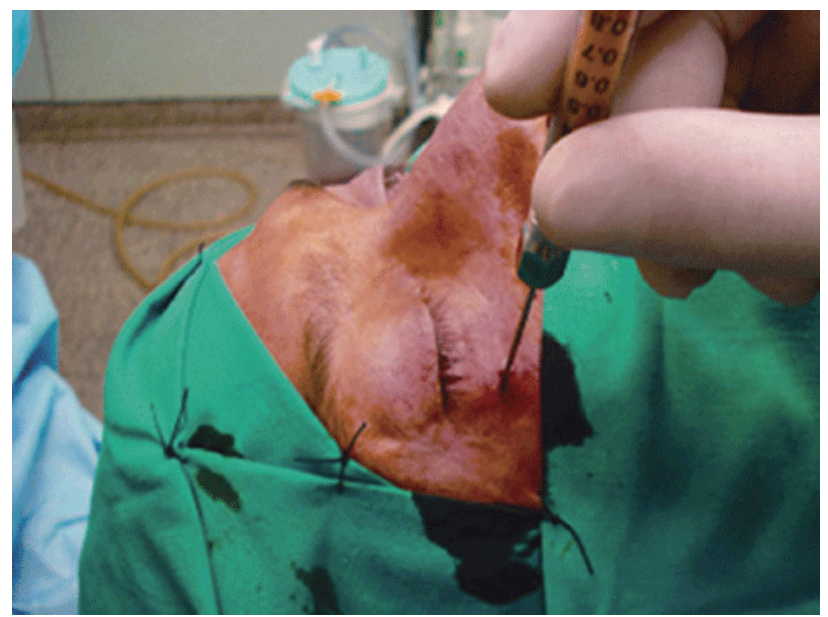

Figure 4: Minimally invasive autologous fat injection: atraumatic suction, furification, and reinjection in the orbit using a cannula. Adapted from Cervelli et $a .^{[50]}$

available for craniofacial surgery since the 1990s. As opposed to porous polyethylene, $\mathrm{HA}$ is more fragile, more expensive, and not as easily shaped intraoperatively. ${ }^{[34]}$ HA appears to have a higher risk of postoperative enophthalmos than medpor. ${ }^{[35]}$ Bioactive glasses (BAGs) are synthetic blocks or granules that bond chemically to bone. Despite the fact that BAGs are of brittle nature and hard to mould and shape, they are osteoinductive and osteoconductive. ${ }^{[36-38]}$ They can prompt the repair of bone with minimal foreign body reaction, infection, extrusion and resorption. ${ }^{39]}$

\section{COMPOSITES}

Composites are an interesting attempt to utilize the advantages of one selected material while reducing its disadvantages with another material. An example is the titanium-reinforced PE. Titanium mesh offers the advantages of high strength and stability, easy contouring, and radiopacity in postoperative imaging, while PE implants have a smooth surface allowing free movement of orbital tissue. ${ }^{[40]}$

\section{SOFT TISSUE FILLING MATERIALS}

As mentioned above, repairing only the fracture is not suffcient. Even if repaired perfectly, many patients may suffer from late sequelae such as enophthalmos due to soft tissue abnormality within the orbit. It's claimed that alterations like atrophy or herniation of soft tissue have a decisive part in the enophthalmos after orbital reconstruction. ${ }^{[41]}$ Thus, we must act to prevent late sequelae by using soft tissue filling materials.
These materials are aimed to replace the abnormal soft tissue and to restore volume of the orbit, to finally restore ocular function as well as aesthetic appearance. They can also be divided into many autologous grafts, allografts, xenografts and alloplastic grafts.

As the "gold standard" of craniofacial reconstruction, autologous bone graft should be the first to be used in this process. However, the rigidity of bone (especially cranium) is relative to the increase of intraocular pressure that might influence the movement of eye and the optic nerve. Furthermore, the donor site morbidity is inevitable.

Silicone oil was one of the first injectable materials placed into the orbit for volume augmentation. Since 1960s, silicone oil has been used for volume augmentation. ${ }^{[42]}$ It's cheap but its outcome is not satisfactory and it needs multiple injections. Many authors have reported complications like extrusion, immigration of implants and infections. ${ }^{\text {|43] }}$

Autologous fat graft (either as free fat or dermal fat graft) has been used since the end of the 19th century to handle various soft-tissue defects. Lipofilling, also known as autologous fat transplantion, has been investigated for a long time, especially as a natural implant for aesthetic and reconstructive purposes. Neuber ${ }^{[44]}$ first used fat autografting to correct facial defects in 1893. He reported a $20 \%$ to $90 \%$ graft absorption rate, so these defects require multiple injections to obtain a satisfactory target. In 1970s, dermal fat transplants were used to fill the orbit. Similarly to other autologous implants, they have outstanding high biocompatibility with minimal infection rate. However, the risk of operation and the donor site morbidity still exist.

In 1980s, collagens injectable became more popular. High resorption grade of non cross-linked collagen gives unsatisfactory results. The use of cross-linked collagen (Zyplast) in the orbital region has a documented risk of blood vessels occlusion, which can lead to a severe visual damage. ${ }^{[45]}$

In the last decade, Hunter and Baker ${ }^{[46]}$ described the use of autologous fat in the orbit for the correction of posttraumatic enophthalmos. The outcome was not good for most of their patients and needed a second injection. Coleman ${ }^{[47,48]}$ reported his technique, defined as atraumatic liposuction with injection of purified fat, for fat transfer: harvesting, purification by centrifugation, and injection. This technique indeed improved the survival rate of fat. Hardy et al. ${ }^{[49]}$ obtained good results in a retrospective study of 12 patients with anophthalmic and enophthalmos; a further injection was necessary in only 1 case. Autologous fat seems to be the ideal filling material for soft tissue defect. Autologous fat is an ideal filler because of its excellent biocompatibility as a living graft, which is easily harvested and incorporated into the surrounding tissues with no hypersensitivity potential and minimal chance of infection. It is readily available in large quantities at low cost, and grafted fat gives a natural consistency with excellent volume augmentation. It is potentially permanent and the regenerative ability of fat is believed to improve the overlying skin quality. Autologous fat 
transfer is minimally invasive, making it more acceptable for patients [Figure 4]. ${ }^{[50]}$ At present, the greatest inconvenience is the unpredictable long term outcome of the graft, related to the extremely variable rate of fat resorption..$^{[51-53]}$ Many animal models have been tried to find the best process of lipofilling. ${ }^{[54-56]}$ However, among the animal models, there is no useful posttraumatic model. Further studies are needed in this field.

We also can choose injectable filler, such as CaHA (Radiesse) or polyacrylamide gel (Aquamid), to treat the soft tissue defect in the orbit. Lately, a patient who received CaHA injection complained of soft tissue swelling. ${ }^{[57]}$ Both of them are reported to be effective in volume augmentation with minimal infections. However, they share the risk of anterior migration of filler. ${ }^{[58-60]}$ We have to take this disadvantage into consideration when choosing the filling material. ${ }^{[61]}$

\section{CONCLUSION}

The controversy about the ideal material for orbital reconstruction and soft tissue defect filling will continue because it's hard to reach consensus due to the limited number of RCTs and studies. New materials emerge often and more studies are needed. We can safely conclude that there is a worldwide trend for surgeons to prefer minimally invasive techniques and alloplastic grafts are becoming increasingly popular.

\section{Financial support and sponsorship}

This article was partially supported by Top Priority Clinical Medical Center of Shanghai Municipal Commission of Health and Family Planning.

\section{Conflicts of interest}

There are no conflicts of interest.

\section{REFERENCES}

I. Chen CT, Chen YR. Update on orbital reconstruction. Curr Opin Otolaryngol Head Neck Surg 2010;18:311-6.

2. Kelley P, Crawford M, Higuera S, Hollier LH. Two hundred ninety-four consecutive facial fractures in an urban trauma center: lessons learned. Plast Reconstr Surg 2005; I 6:e42-9.

3. Lang W.Traumatic enophthalmos with retention of perfect acuity of vision. Trans Ophthalmol Soc UK 1889;9:4I.

4. Ramieri G, Spada MC, Bianchi SD, Berrone S. Dimensions and volumes of the orbit and orbital fat in posttraumatic enophthalmos. Dentomaxillofac Radiol 2000;29:302-II.

5. Dubois L, Steenen SA, Gooris PJ, Bos RR, Becking AG. Controversies in orbital reconstruction-III. Biomaterials for orbital reconstruction: a review with clinical recommendations. Int J Oral Maxillofac Surg 2016;45:41-50.

6. Gunarajah DR, Samman N. Biomaterials for repair of orbital floor blowout fractures: a systematic review.J Oral Maxillofac Surg 2013;71:550-70.

7. van Leeuwen AC, Ong SH,Vissink A, Grijpma DW, Bos RR. Reconstruction of orbital wall defects: recommendations based on a mathematical model. Exp Eye Res 2012;97:10-8.

8. Wajih WA, Shaharuddin B, Razak NH. Hospital Universiti Sains Malaysia experience in orbital floor reconstruction: autogenous graft versus medpor.J Oral Maxillofac Surg 201 I;69:1740-4

9. Schlickewei W, Schlickewei C.The use of bone substitutes in the treatment of bone defects - the clinical view and history. Macromol Symp 2007;253:1023.

10. Tessier P, Woillez M, Lekieffre M, Asseman R. Posttraumatic diplopia and osseous grafts. Observations. Bull Mem Soc Fr Ophtalmol 1960;73: 271-91. (in French)
II. Kosaka M, Matsuzawa Y, Mori H, Matsunaga K, Kamiishi H. Orbital wall reconstruction with bone grafts from the outer cortex of the mandible.J Craniomaxillofac Surg 2004;32:374-80.

12. Lee HH, Alcaraz N, Reino A, Lawson W. Reconstruction of orbital floor fractures with maxillary bone. Arch Otolaryngol Head Neck Surg 1998; 1 24:56-9.

13. Kontio RK, Laine P, Salo A, Paukku P, Lindqvist C, Suuronen R. Reconstruction of internal orbital wall fracture with iliac crest free bone graft: clinical, computed tomography, and magnetic resonance imaging follow-up study. Plast Reconstr Surg 2006; I 18:1365-74.

14. Ilankovan V, Jackson IT. Experience in the use of calvarial bone grafts in orbital reconstruction. Br J Oral Maxillofac Surg 1992;30:92-6.

15. Zins JE,Whitaker LA. Membranous versus endochondral bone: implications for craniofacial reconstruction. Plast Reconstr Surg 1983;72:778-85.

16. Castellani A, Negrini S, Zanetti U. Treatment of orbital floor blowout fractures with conchal auricular cartilage graft: a report on 14 cases.J Oral Maxillofac Surg 2002;60:1413-7.

17. Lai A, Gliklich RE, Rubin PA. Repair of orbital blow-out fractures with nasoseptal cartilage. Laryngoscope 1998; 108:645-50.

18. Baranov IV, Devdariani DSh, Kulikov AV, Aleksandrov AB, Bagnenko AS Surgical treatment of posttraumatic deformity of the orbital floor. Vestn Khir Im I I Grek 20I I; I70:63-5. (in Russian)

19. Bayat M, Momen-Heravi F, Khalilzadeh O, Mirhosseni Z, Sadeghi-Tari A Comparison of conchal cartilage graft with nasal septal cartilage graft for reconstruction of orbital floor blowout fractures. Br J Oral Maxillofac Surg 20I0;48:6I7-20.

20. Luhr HG, Maerker R.Transplantation of homologous dura in reconstruction of the orbital floor. Trans Int Conf Oral Surg 1973;4:340-4.

21. Centers for Disease Control (CDC). Rapidly progressive dementia in a patient who received a cadaveric dura mater graft. MMWR Morb Mortal Wkly Rep 1987;36:49-50, 55.

22. Chowdhury K, Krause GE. Selection of materials for orbital floor reconstruction. Arch Otolaryngol Head Neck Surg 1998; I24:1398-40।.

23. Aho AJ, Hirn M, Aro HT, Heikkilä JT, Meurman O. Bone bank service in Finland. Experience of bacteriologic, serologic and clinical results of the Turku Bone Bank 1972-1995. Acta Orthop Scand 1998;69:559-65.

24. Campbell DG, Li P. Sterilization of HIV with irradiation: relevance to infected bone allografts. Aust N Z J Surg 1999;69:517-2I.

25. Baino F. Biomaterials and implants for orbital floor repair. Acta Biomater 201।;7:3248-66.

26. Sullivan PK, Smith JF, Rozzelle AA. Cranio-orbital reconstruction: safety and image quality of metallic implants on CT and MRI scanning. Plast Reconstr Surg 1994;94:589-96.

27. Ellis E 3rd, Messo E. Use of nonresorbable alloplastic implants for internal orbital reconstruction.J Oral Maxillofac Surg 2004;62:873-8I.

28. Lieger O, Richards R, Liu M, Lloyd T. Computer-assisted design and manufacture of implants in the late reconstruction of extensive orbital fractures. Arch Facial Plast Surg 2010; 12:186-91.

29. Schubert W, Gear AJ, Lee C, Hilger PA, Haus E, Migliori MR, Mann DA Benjamin $\mathrm{Cl}$. Incorporation of titanium mesh in orbital and midface reconstruction. Plast Reconstr Surg 2002; I 10:1022-30; discussion 1031-2.

30. Lipshutz $\mathrm{H}$, Ardizone RA. The use of silicone rubber in the immediate reconstruction of fractures of the floor of the orbit. J Trauma 1963;3:563-8.

31. Polley JW, Ringler SL. The use of teflon in orbital floor reconstruction following blunt facial trauma: a 20-year experience. Plast Reconstr Surg 1987;79:39-43.

32. Browning CW, Walker RV. Polyethylene in posttraumatic orbital floor reconstruction. Am J Ophthalmol 1961;52:672-7.

33. Park DJ, Garibaldi DC, Iliff NT, Grant MP, Merbs SL. Smooth nylon foil (SupraFOIL) orbital implants in orbital fractures: a case series of 181 patients. Ophthal Plast Reconstr Surg 2008;24:266-70.

34. Bae YC, Choi SJ, Moon JS, Nam SB. Comparison of the postoperative outcome in pure medial orbital fracture among three groups: using porous polyethylene or hydroxyapatite through subciliary approach and transnasal endoscopic correction. Ann Plast Surg 2007;59:287-90.

35. Nam SB, Bae YC, Moon JS, Kang YS. Analysis of the postoperative outcome in 405 cases of orbital fracture using 2 synthetic orbital implants. Ann Plast Surg 2006;56:263-7.

36. Peltola M, Kinnunen I, Aitasalo K. Reconstruction of orbital wall defects with bioactive glass plates.J Oral Maxillofac Surg 2008;66:639-46.

37. Heikkilä JT, Aho HJ, Yli-Urpo A, Happonen RP, Aho AJ. Bone formation in rabbit cancellous bone defects filled with bioactive glass granules. Acto Orthop Scand 1995;66:463-7.

38. Aitasalo K, Kinnunen I, Palmgren J, Varpula M. Repair of orbital floor fractures with bioactive glass implants. J Oral Maxillofac Surg 200 I;59:13905; discussion 1395-6. 
39. Amato MM, Blaydon SM, Scribbick FW Jr, Belden CJ, Shore JW, Neuhaus RW, Kelley PS, Holck DE. Use of bioglass for orbital volume augmentation in enophthalmos: a rabbit model (oryctolagus cuniculus). Ophthal Plast Reconstr Surg 2003; 19:455-65.

40. Zhang L, Fay A. Composite implants in oculoplastic surgery. Semin Ophthalmol 2010;25:303-8.

41. Grant MP, Iliff NT, Manson PN. Strategies for the treatment of enophthalmos. Clin Plast Surg 1997;24:539-50.

42. Chasan PE. The history of injectable silicone fluids for soft-tissue augmentation. Plast Reconstr Surg 2007; 1 20:2034-40; discussion 204 I-3.

43. Laiseca A, Laiseca D, Laiseca J, Laiseca J Jr. Correcting superior sulcus deformities. Adv Ophthalmic Plast Reconstr Surg 1990;8:229-42.

44. Neuber GA. Fett transplantation. Verh Dtsch Ges Chir 1893:22-66.

45. Cahill KV, Burns JA. Volume augmentation of the anophthalmic orbit with cross-linked collagen (Zyplast). Arch Ophthalmol 1989;107:1684-6.

46. Hunter PD, Baker SS. The treatment of enophthalmos by orbital injection of fat autograft. Arch Otolaryngol Head Neck Surg 1994; 120:835-9.

47. Coleman SR. Long-term survival of fat transplants: controlled demonstrations. Aesthetic Plast Surg 1995; 19:421-5.

48. Coleman SR. Facial recontouring with lipostructure. Clin Plast Surg 1997;24:347-67.

49. Hardy TG, Joshi N, Kelly MH. Orbital volume augmentation with autologous micro-fat grafts. Ophthal Plast Reconstr Surg 2007;23:445-9.

50. Cervelli D, Gasparini G, Moro A, Grussu F, Boniello R, Pelo S. Retrobulbar lipofilling to correct the enophthalmos.J Craniofac Surg 201 1;22:1918-22.

5I. Coleman SR. Structural fat grafting: more than a permanent filler. Plast Reconstr Surg 2006; II8:s108-20.

52. Smith P, Adams WP Jr, Lipschitz AH, Chau B, Sorokin E, Rohrich RJ, Brown SA. Autologous human fat grafting: effect of harvesting and preparation techniques on adipocyte graft survival. Plast Reconstr Surg 2006; I 17:1836-
44.

53. Moseley TA, Zhu M, Hedrick MH. Adipose-derived stem and progenitor cells as fillers in plastic and reconstructive surgery. Plast Reconstr Surg 2006; I 18:s | 21-8.

54. Cakir B, Aygit AC, Omur-Okten O, Yalcin O. Retro-orbital intraconal fat injection: an experimental study in rabbits. J Oral Maxillofac Surg 20I 2;70:242-50

55. Lee JY, Lee KH, Shin HM, Chung KH, Kim GI, Lew H. Orbital volume augmentation after injection of human orbital adipose-derived stem cells in rabbits. Invest Ophthalmol Vis Sci 2013;54:24I0-6.

56. Brown M, Lee M, Zwiebel S, Adenuga P, Molavi S, Gargesha M, Varghai D, Guyuron B. Augmentation of intraorbital volume with fat injection. Plast Reconstr Surg 2014;133:1098-106.

57. Rauso R.A unique late complication with the use of calcium hydroxylapatite filler in facial lipoatrophy rehabilitation. Plast Aesthet Res 2014; I: 122.

58. Vagefi MR, McMullan TF, Burroughs JR, Georgescu D, McCann JD, Anderson RL. Orbital augmentation with injectable calcium hydroxylapatite for correction of postenucleation/evisceration socket syndrome. Ophthal Plast Reconstr Surg 201 I;27:90-4.

59. da Silva AL, Bredemeier M, Gebrim ES, Moura Eda M. Intraorbital polyacrylamide gel injection for the treatment of anophthalmic enophthalmos. Ophthal Plast Reconstr Surg 2008;24:367-7I.

60. Buchanan AG, Holds JB, Vagefi MR, Bidar M, McCann JD, Anderson RL. Anterior filler displacement following injection of calcium hydroxylapatite gel (Radiesse) for anophthalmic orbital volume augmentation. Ophthal Plast Reconstr Surg 2012;28:335-7.

61. Vagefi MR. Minimally invasive approaches to orbital volume augmentation. Int Ophthalmol Clin 2013;53:67-86. 